\title{
POPULACAO MARGINALIZADA NA AREA CENTRAL DE PRESIDENTE PRUDENTE-SP
}

Felipe Gasquez de Morais, Maria Gabriela Salvino Contre, Moisés Henrique dos Santos Leonel, Victor Martins de Aguiar, Yeda Ruiz Maria.

Universidade do Oeste Paulista - UNOESTE, Curso de Arquitetura e Urbanismo, Presidente Prudente, SP. E-mail: yeda_rm@hotmail.com

\section{RESUMO}

As apropriações dos espaços públicos são como um mecanismo de defesa e superação da população aos modelos urbanísticos impostos. Na cidade de Presidente Prudente-SP, como produto da atratividade comercial e constante fluxo de pessoas, atividades variadas foram surgindo, dentre elas apropriações de pessoas marginalizadas, como prostituição de rua, usuários de drogas ilícitas e moradores em situação de rua. Para a compreensão das relações entre os modos de apropriação dos espaços públicos, o presente artigo propõe analisar a área central da cidade de Presidente Prudente em busca de entender como os espaços públicos tem-se transformado nesta área. Para isso, foram realizados mapeamentos dos espaços públicos que estão sendo apropriados e observações in loco para entender as formas de apropriação da população marginalizada.

Palavras-chave: População Marginalizada; Área Central; Espaços Públicos; Presidente Prudente.

\section{MARGINALIZED POPULATION IN THE CENTRAL AREA OF PRUDENT PRESIDENT-SP}

\section{ABSTRACT}

The appropriations of the public spaces are like a mechanism of defense and overcoming of the population to the urban models imposed. In the city of Presidente Prudente - SP, as a product of commercial attractiveness and constant flow of people, varied activities were emerging, among them appropriations of marginalized people, such as street prostitution, illicit drug users and street dwellers. To understand the relationship between the ways of appropriating in public spaces, this article proposes an analysis of the central area of the city of Presidente Prudente - SP, in an attempt to understand how public spaces have transformed in this area. For this, mapping of the public spaces that are being appropriated and observation in loco to understand the urban structure offered by the place will be essential for the perception.

Keywords: Marginalized Population; Central Area; Public spaces; Presidente Prudente - SP.

\section{INTRODUÇÃO}

A área central de Presidente Prudente apresenta uma carga histórica de uso do espaço já conhecido pelos habitantes da cidade. De acordo com Resende (2006), na década de 1940, o comércio se consolidou como o principal setor econômico da região, pois os produtos plantados pelos moradores eram vendidos nos armazéns distribuídos na área central, entretanto, a partir da década de 1950, esse perfil mudou e, as lojas especializadas cresceram e tomaram conta do comércio.

$\mathrm{Na}$ década 1960, nessa região encontravam-se hotéis e bares. Na Avenida
Brasil, por exemplo, já em 1970, foi inaugurado à rodoviária e o terminal urbano (SILVA; SIMÕES, 2007). Em virtude da atratividade comercial e consequente fluxo de pessoas, atividades variadas foram surgindo, dentre elas a prostituição de rua, usuários de drogas ilícitas e moradores em situação de rua.

No final do século XIX e início do século XX, de acordo com Rago (1998), a prostituição ganhou espaço na sociedade brasileira. Grandes bordéis e zonas de meretrícios foram construídos e frequentados por homens de várias classes sociais. Os lugares de prostituição, tais como cabarés, café-encontros, "pensões chiques", 
teatros e restaurantes estabeleceram uma grande rede de sociabilidade e de vida pública. Mas, a modernidade, para Braz (2011), se apropriou da prostituição, inovando as formas de prostituir, formando novos territórios e meios para seu desenvolvimento.

Esses usos, pouco a pouco, promoveram um esvaziamento das pessoas que residiam à área central de Presidente Prudente, por conta da insegurança e do preconceito, e suas antigas residências se tornaram casas de prostituição. Estabelecendo assim, o início da estagnação econômica da área e a apropriação pela população marginalizada.

O presente artigo conceitua a marginalização, segundo as palavras de Pereira (1979), o qual esclarece ser um termo da sociologia que está relacionado com a exclusão, seja social, cultural, política, econômica. Os indivíduos marginalizados, ou seja, os que sofrem o processo de marginalização são chamados popularmente de "marginais", "vadios" ou "indigentes". Os indivíduos que compõem o conjunto dos marginalizados não escolhem tal posição e, na maioria das vezes, sofrem hostilidades, discriminações, preconceitos e violência que causam diversos problemas à sua vida. Vale citar alguns exemplos de pessoas marginalizadas: pobres, desempregados, homossexuais, travestis, imigrantes, negros, deficientes, idosos, dentre outros (PEREIRA, 1979).

Neste contexto, tem-se como objetivo, levantar os possíveis locais que estejam sendo reestruturados pelas apropriações da população tida como marginal na área central de Presidente Prudente - SP.

\section{METODOLOGIA}

O desenvolvimento do trabalho se deu através de consultas em fontes de dados secundárias, como livros, artigos e sites da Internet, com 0 intuito de compor o embasamento teórico sobre: população marginal, espaço público e estagnação urbana. Para melhor compreensão da hipótese colocada foi necessário contextualizar a área de estudo, assim, foram realizados levantamentos de campo, além de observações in loco nos espaços públicos da área central. Essas observações variaram entre diferentes horários e dias, afim de entender a relação do usuário e apropriadores da área em estudo.

\section{A AREA CENTRAL DE PRESIDENTE PRUDENTE -SP}

O centro de Presidente Prudente - SP é caracterizado por ser o núcleo inicial da cidade (FIGURA 1), ele apresenta uma carga histórica bastante significativa, seja ela física ou de memória coletiva. Também foi nele se deu o início do comércio, onde o mesmo se consolidou tornando-se um dos principais polos industriais, culturais e de serviços do Oeste Paulista. Além das características comerciais e serviços mais tradicionais, igreja matriz e órgãos municipais, o Centro é o principal ponto de interação entre as frotas de transporte público.

Figura 1. Imagem Via Satélite de Presidente Prudente - SP, destacando o quadrilátero central.

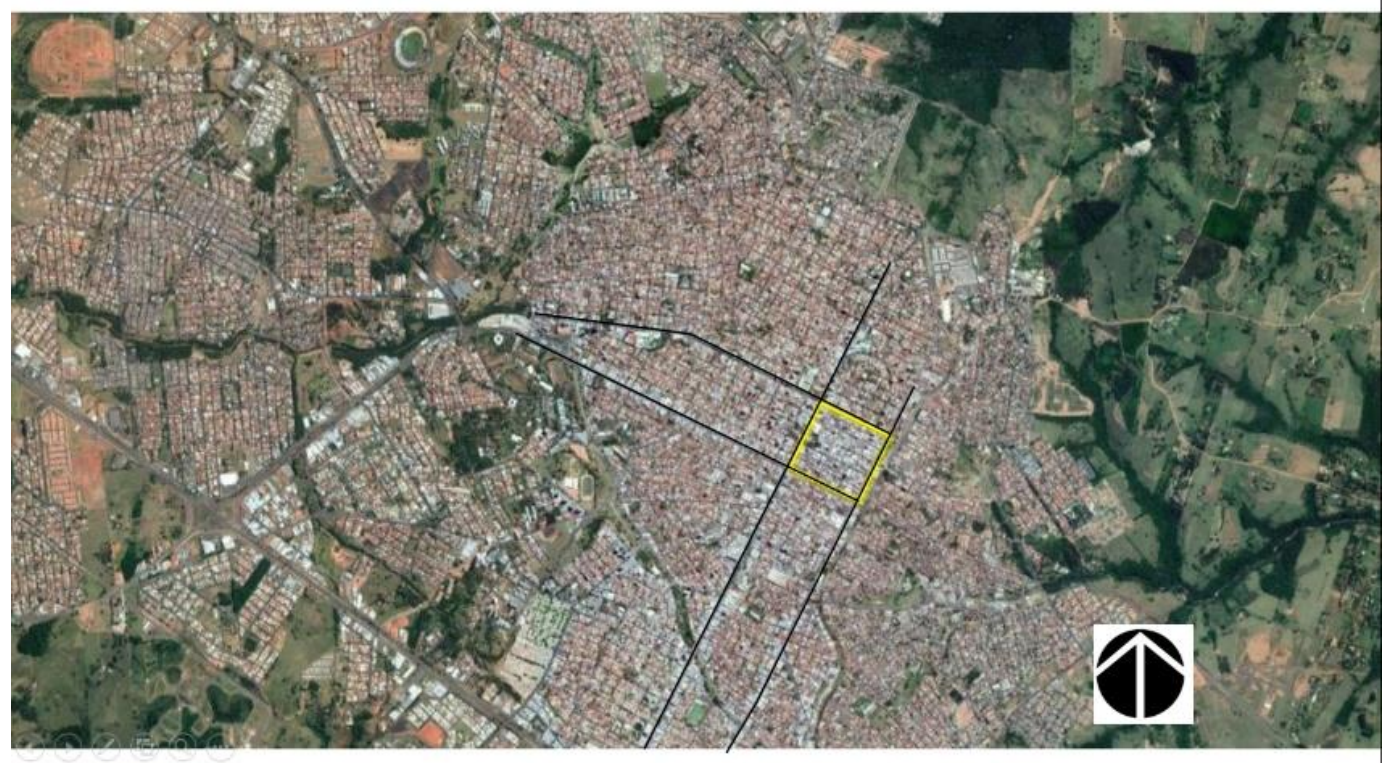

Fonte: Google Maps, 2018. Editado pelos autores, 2018. 
Diante desses fatos, nota-se 0 esvaziamento do centro para os moradores e uma tendência ao afastamento dos transeuntes. O quadrilátero central de Presidente Prudente tem seu funcionamento das 9 horas às 18 horas de segunda a sábado, permanecendo fechado integralmente nos domingos e feriados. Assim, é possível fazer uma relação entre o horário de funcionamento do Centro e a aparições das atividades de população marginalizada, ou seja, a operação central influencia diretamente na dinâmica dessa população (FIGURA 2).

Figura 2. Movimentação de atividade da população marginal do centro de Presidente Prudente - SP.

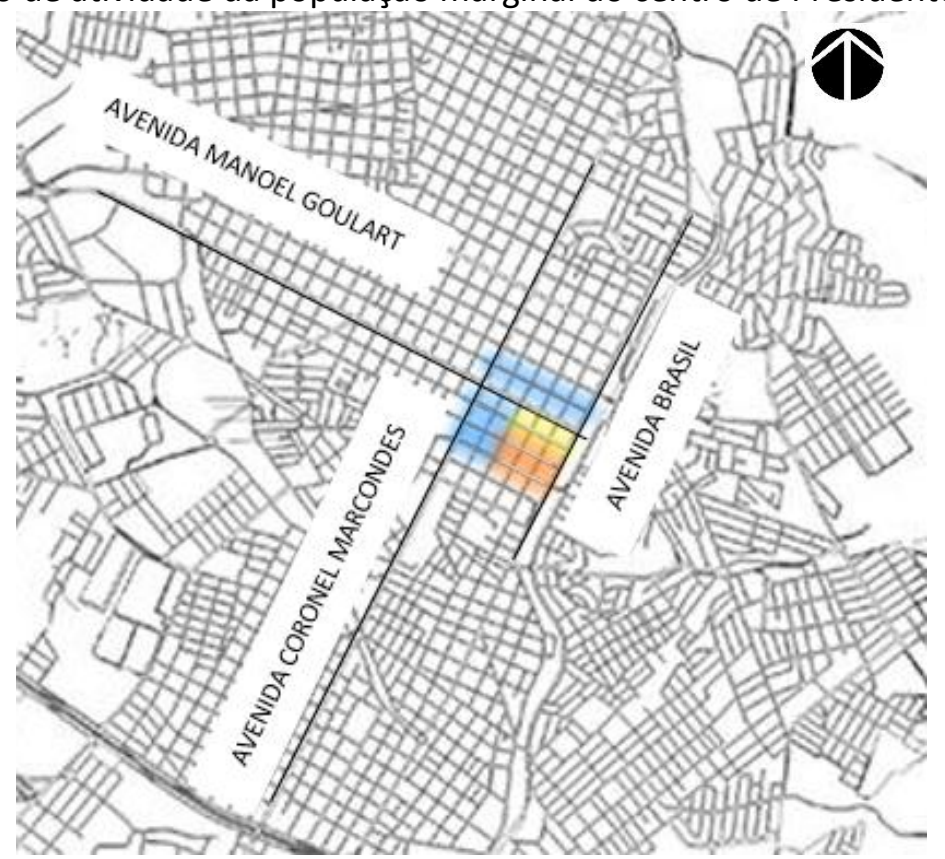

Movimentações noturna

Movimentações em períodos diurnos

Observados mistos entre horários diferentes.

Fonte: Prefeitura Municipal de Presidente Prudente - SP, 2004. Editado pelos autores, 2018.

É possível notar que as áreas com maior intensidade estão inseridas no cruzamento entre a Avenida Coronel Marcondes e a Avenida Manoel Goulart, no entanto essas atividades são noturnas, período que já não existe fluxo comercial e quase nenhum movimento. Entendese, portanto, que o uso do espaço público é flexível, objetos de apropriações diferenciadas, mesmo que formalmente constituídos para finalidade específica.

Apesar de flexível, na área objeto da pesquisa não foram observadas tipo de apropriações que levam a vida ao espaço urbano, misto de uso e ocupações que entendem o lugar como pertencente. Vogel et al. (1985) caracterizam a rua através de uma abordagem física, morfológica, no âmbito do espaço público e respectiva apropriação, apontando-a como uma extensão da casa para diversas comunidades, observadas e vivenciadas por meio de atividades cotidianas, como as brincadeiras infantis e encontros de vizinhos, ou sazonais, como as festas. Desse modo, a área central em períodos divergentes ao funcionamento comercial, se torna cada vez mais ociosa abrindo espaço para apropriações indesejáveis.

Além disso, nos levantamentos in loco da pesquisa foram observadas apropriações organizadas, mesmo que de forma não intencional na tipologia de uso marginal (FIGURA $3)$. 
Figura 3: A imagem mostra tipologias de ocupações na área central por populações marginais em Presidente Prudente - SP.

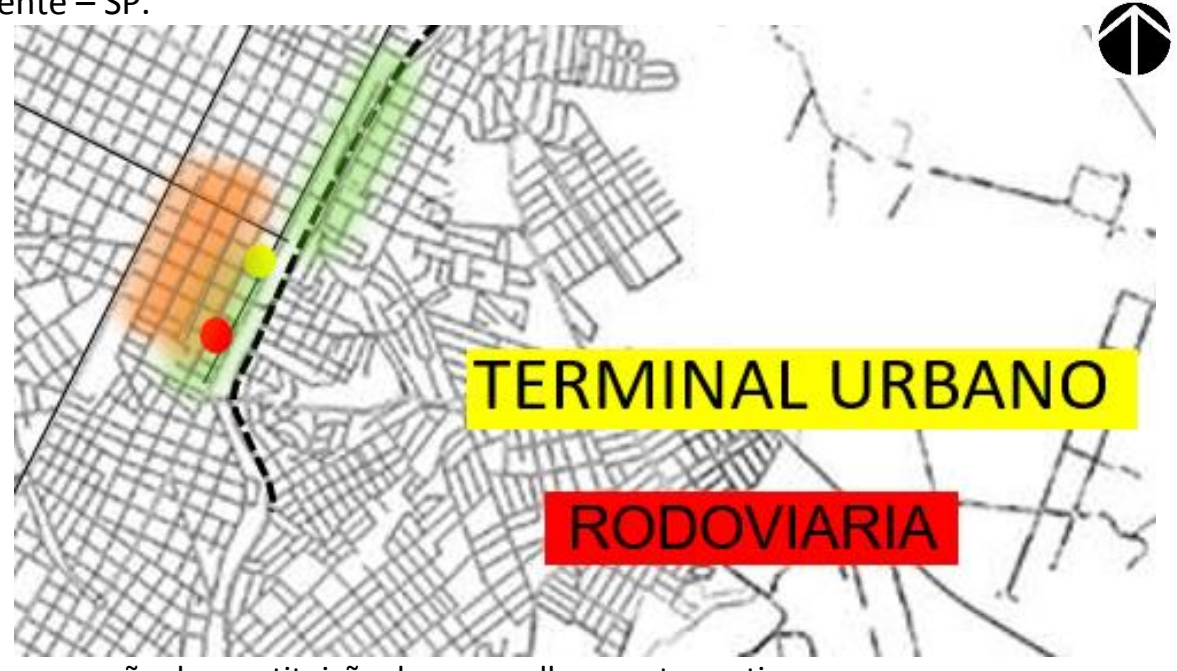

Caracteriza-se pela ocupação de prostituição de rua, mulheres e travestis.

Caracteriza-se por ocupações de usuários de drogas.

Linha férrea, atualmente sem uso. --.

Fonte: Prefeitura Municipal de Presidente prudente - SP, 2004. Editado pelos autores, 2018.

\section{RESULTADOS}

O uso da malha urbana de Presidente Prudente - SP para a prostituição e a população usuária de drogas ilícitas não se situam nos mesmos locais, salvo as mulheres que são usuárias e tem a prostituição como modo de sustentar o vício.

É notável que a forma de apropriação esteja diretamente ligada ao uso do solo urbano, visto que a população que o utiliza para prostituição prefere locais com movimento preferencialmente de carros. A prostituição acaba se dando próxima às grandes avenidas, mas que não as deixam expostas a possíveis violências moral e/ou física.

Esse Centro, segundo Martins (2011), é o Centro equipado, valorizado e com grande oferta de empregos, têm lugar às disputas territoriais associadas a um quadro edificado que se torna obsoleto para alguns tipos de usos, ficando sujeito à precarização pelo envelhecimento sem manutenção e ao abandono.

Em oposição a essa forma de usufruir da degradação do Centro, identifica-se que usuários de drogas preferem espaços nos quais não existe quase nenhum fluxo, e se existir é uma passagem rápida. Esses espaços estão juntos ou próximos de locais que propiciam a essa forma espacial de fluxo, como a rodoviária e terminal urbano de ônibus, ou aquele que já não existe nenhum uso, a linha férrea.

É de conhecimento que as atuais apropriações do Centro, principalmente de usuários, têm uma tendência a aumentar a violência urbana como, assaltos, estupros e conflitos de traficantes por território reforçam a falta de dinâmica central. Assim, o mercado imobiliário vende a falsa ideia de segurança, incentivando ainda mais a saída de moradores desse raio central, e se apropria da "violência urbana" nos seus discursos e análises, que está diretamente ligada à indústria da segurança (SAMPAIO, 2011).

A compreensão da área estudada, a partir de seus usos, é de que a maneira em que se dá o fluxo, seja ele de carro ou de pedestre, leva a população marginal ali presente recorrer a um lugar degradado que por falta de incentivos da administração pública, não promove nenhum senso comunitário, valor histórico ou sensação de pertencimento local.

\section{CONSIDERACOES FINAIS}

Conclui-se que há vários fatores que contribuem para uma formação e uso negativo do espaço urbano: planejamento falho, falta de incentivo ao uso noturno e a valorização histórica.

Ao longo da história prudentina, estabeleceu uma memória negativa sobre a área central e seu entorno, que também contribui para esse efeito. Assim, a insegurança se torna algo cada vez mais comum dentro de um espaço que não é dinâmico, agradável, ou não apresenta nenhum equipamento para a sua utilização.

A resposta vem então em forma de apropriações 
indesejáveis, como a prostituição de rua e a população marginal. Vale ressaltar que esse artigo não tem nenhuma intenção de julgar as atividades ali presentes, cada setor da cidade deve ser equipado com infraestrutura adequada, e a população tem o direito de usufruir.

\section{REFERENCIAS}

BRAZ, S. Prostituição Feminina: história e territorialidades no espaço urbano de Teresina. Geografia Tempo Espaço e Cultura, 5 mar. 2011. Disponível em: <https://geografiaespacotempoecultura.wordpre ss.com/2011/03/05/prostituicao-femininahistoria-e-territorialidades-no-espaco-urbano-deteresina/>. Acessado em: 20 jul. 2018.

MARTINS, M. L. R. São Paulo, centro e periferia: a retórica ambiental e os limites da política urbana. Estudos Avançados, v. 25, n. 71,p. 59-72, 2011.

MENDONÇA, E. M. S. Apropriações do espaço público: alguns conceitos. Estudos e Pesquisas em Psicologia, UERJ, RJ, v. 7, n. 2, p. 296-306, ago. 2007.

PEREIRA, Luiz. (Org) Roberto Motta. População Marginal. v.7, 1979.

RAGO, M. Epistemologia feminista, gênero e história. In: PEDRO, J. M.; GROSSI, M. P. (Orgs.). Masculino, feminino, plural. Florianópolis: Editora Mulheres, 1998.

RESENDE, B. Raízes Prudentinas. Presidente Prudente: Gráfica Impress, 2006.

SAMPAIO, R. A. Da noção de violência urbana à compreensão da violência do processo de urbanização: apontamentos para uma inversão analítica a partir da geografia urbana. 2011. Dissertação (Mestrado em Geografia Humana) Faculdade de Filosofia, Letras e Ciências Humanas, Universidade de São Paulo, São Paulo, 2011. doi:10.11606/D.8.2012.tde29082012-103945.

VOGEL, A.et al. (coords.) Quando a rua vira casa: a apropriação de espaços de uso coletivo em um centro de bairro. Rio de Janeiro: FINEP/IBAM, Projeto, 1985.
Recebido para publicação em 09/08/2018

Revisado em 22/08/2018

Aceito em 04/09/2018 